\title{
Adjuvant chemoradiotherapy of advanced resectable rectal cancer: results of a randomised trial comparing modulation of 5-fluorouracil with folinic acid or with interferon- $\alpha$
}

\author{
M Kornmann*,', L Staib ${ }^{2}$, T Wiegel ${ }^{3}$, E-D Kreuser ${ }^{2}$, M Kron $^{4}$, W Baumann², D Henne-Bruns' and K-H Link ${ }^{2}$ \\ 'Department of General, Visceral, and Transplantation Surgery, University of Ulm, Steinhoevelstrasse, Ulm 89075, Germany; ${ }^{2}$ Study Group Oncology \\ of Gastrointestinal Tumors (FOGT), Wiesbaden 65197, Germany; ${ }^{3}$ Department of Radiation Oncology, University of Ulm, Ulm 89075, Germany; \\ ${ }^{4}$ Institute of Biometrics, University of Ulm, Ulm 89075, Germany
}

\begin{abstract}
BACKGROUND: Standard adjuvant chemoradiotherapy of rectal cancer still consists of 5-fluorouracil (5-FU) only. Its cytotoxicity is enhanced by folinic acid (FA) and interferon- $\alpha$ (INF $\alpha$ ). In this trial, the effects of FA and IFN $\alpha$ on adjuvant 5-FU chemoradiotherapy in locally advanced rectal cancer were investigated.

METHODS: Patients with $R_{0}$-resected rectal cancer (UICC stage II and III) were stratified and randomised to a I2-month adjuvant chemoradiotherapy with 5-FU, 5-FU + FA, or 5-FU + IFN $\alpha$. All patients received levamisol and local irradiation with $50.4 \mathrm{~Gy}$.

RESULTS: Median follow-up was 4.9 years $(n=796)$. Toxicities (WHO III + IV) were observed in 32,28 , and $58 \%$ of patients receiving 5-FU, 5-FU + FA, and 5-FU + IFN $\alpha$, respectively. No differences between the groups were observed for local or distant recurrence. Five-year overall survival (OS) rates were 60.3\% (95\% confidence interval (Cl): 54.3-65.8), 60.4\% (54.4-65.8), and 59.9\% (53.0-66.I) for 5-FU, 5-FU + FA, and 5-FU + IFN $\alpha$, respectively. A subgroup analysis in stage II (pT3/4pN0) disease $(n=27 \mathrm{I})$ revealed that the addition of FA tended to reduce the 5 -year local recurrence (LR) rate by $55 \%$ and increase recurrence-free survival and $O S$ rates by 12 and $13 \%$, respectively, relative to 5 -FU alone.

CONCLUSIONS: Interferon- $\alpha$ cannot be recommended for adjuvant chemoradiotherapy of rectal cancer. In UICC stage II disease, the addition of FA tended to lower LR and increased survival. The addition of FA to 5-FU may be an effective option for adjuvant chemoradiotherapy of UICC stage II rectal cancer.
\end{abstract}

British Journal of Cancer (2010) I03, II63- | 172. doi:I0.1038/sj.bjc.660587| www.bjcancer.com

Published online 28 September 2010

(c) 2010 Cancer Research UK

Keywords: rectal cancer; adjuvant chemoradiotherapy; 5-fluorouracil; interferon; folinic acid

During the last two decades, treatment strategies of rectal cancer have improved markedly. Although in the early 1990s local recurrence (LR) rates beyond $20 \%$ and overall recurrence rates beyond 50\% were reported for UICC stage II and III (Gastrointestinal Tumor Study Group, 1985; Fisher et al, 1988; Krook et al, 1991), multimodal approaches were shown to increase local control and survival (Swedish Rectal Cancer Trial, 1997; Wolmark et al, 2000). In parallel, total mesorectal excision (TME), including the complete removal of the fatty tissue and lymph nodes surrounding the rectum, was introduced resulting in a significant improvement of local control (Martling et al, 2000; Wibe et al, 2002). Local recurrence rates were further decreased in locally advanced rectal cancer using neoadjuvant strategies compared with the adjuvant setting (Sauer et al, 2004) or combining radiation with chemotherapy (Bosset et al, 2006; Gérard et al, 2006). In contrast to the old resection technique (Swedish Rectal Cancer Trial, 1997), the addition of neoadjuvant radiation to modern TME surgery reduced LR, but did not improve survival (Peeters et al, 2007).

\footnotetext{
*Correspondence: Professor M Kornmann;

E-mail: marko.kornmann@uniklinik-ulm.de

Received I4 June 2010; revised 30 July 20I0; accepted 2 August 2010; published online 28 September 2010
}

Irrespective of pre- or postoperative (chemo)radiation, distant metastases still occur in about $40 \%$ of locally advanced rectal cancers (Swedish Rectal Cancer Trial, 1997; Wolmark et al, 2000; Tepper et al, 2002; Sauer et al, 2004; Peeters et al, 2007). In order to improve prognosis, systemic treatment of these patients has to be optimised (Weiss et al, 2009). Marked advances in adjuvant treatment have been achieved in colon cancer during the last two decades (IMPACT investigators, 1995; Porschen et al, 2001; Haller et al, 2005; Link et al, 2005; Kuebler et al, 2007; André et al, 2009). Despite the clear benefit of 5-fluorouracil (5-FU) modulation by folinic acid (FA) in colon cancer (IMPACT investigators, 1995; Porschen et al, 2001; Haller et al, 2005; Link et al, 2005), a clear benefit of this combination in rectal cancer could not be shown (QUASAR Collaborative Group, 2000; Wolmark et al, 2000; Tepper et al, 2002; Dahl et al, 2009). Standard chemoradiotherapy of rectal cancer (UICC stage II and III) is often still carried out using 5-FU monotherapy (de Gramont and Haller, 2008).

5 -Fluorouracil toxicity is modulated by FA and interferon- $\alpha$ $($ IFN $\alpha$ ) (Corfu-A Study Group, 1995; Van Triest et al, 2000). Among several other mechanisms, FA increases the concentration of the cofactor 5,10-methylenetetrahydrofolate, thereby stabilising the ternary complex formation of 5 -fluoro- $2^{\prime}$-deoxyuridine$5^{\prime}$-monophosphate, with thymidylate synthase inhibiting DNA synthesis (Van Triest et al, 2000), whereas INF $\alpha$ enhances 5-FU 
metabolism and, moreover, has immunomodulating and antiangiogenic effects (Makower and Wadler, 1999; Slaton et al, 1999). The aim of this trial was to improve adjuvant chemoradiotherapy of rectal cancer by modulating 5-FU with either FA or IFN $\alpha$. Secondary aims were to characterise toxicity of the regimens and identify clinical and pathological parameters influencing recurrence and prognosis.

\section{PATIENTS AND METHODS}

\section{Ethics}

The German 'Research Group Oncology of Gastrointestinal Tumors' (FOGT) designed a prospective randomised trial (FOGT-2) to optimise adjuvant treatment of rectal cancer conform to GCP/ICH rules and respecting the Helsinki Declaration (1989) to improve adjuvant treatment of locally advanced rectal cancer. It was approved by the Ethics Committee of the University of Ulm No. 87/91) and supervised by an independent study monitor. A similarly designed trial (FOGT-1) was performed in colon cancer (Link et al, 2005).

\section{Patient eligibility criteria}

Patients had a medical history, physical examination, ECG, colonoscopy, complete blood cell count, and chemistry, including liver and renal function parameters and carcinoembryonic antigen. Distant metastases were excluded by abdominal ultrasound, chest $\mathrm{X}$-ray, and intraoperative liver palpation. Computed tomography or MRI scans were optional.

Eligibility was defined as potentially curative en bloc resection $\left(R_{0}\right)$ of an adenocarcinoma of the rectum with a lower tumour edge within $12 \mathrm{~cm}$ from the anal verge determined by rectoscopy, a pathological UICC stage II (pT3/4pN0M0) or III (pT1-4pNposM0) with examination of at least 12 lymph nodes, a white blood count $\geqslant 3500 \mu \mathrm{l}^{-1}$, a platelet count $\geqslant 100000 \mu \mathrm{l}^{-1}$, a ECOG performance status of 0 or 1 , and written informed consent. Ineligible were patients not fulfilling these criteria or having a history of cancer, except for adequately treated superficial basal or squamous cell skin cancer or in situ carcinoma of the cervix, getting previous radio- or chemotherapy, pregnant or nursing women, others having severe concomitant diseases limiting life expectancy or not allowing chemotherapy, and with social conditions not allowing a 5-year follow-up.

\section{Surgical procedures}

Anterior resections (AR) including Hartmann procedures and abdominoperineal resections (APR) had to be performed according to the recommendations of the German Cancer Society (Herfahrt and Schlag, 1991). A distal free resection margin of $3 \mathrm{~cm}$ was required for ARs and a wide resection of the levators close to the pelvis wall in case of APRs.

\section{Pathological evaluation}

The fourth version of the UICC/TNM classification was used to document the pathological staging. Results in this paper are reported according to the sixth version. Overall, 57 patients initially documented as $\mathrm{pN} 3$ (central positive lymph nodes, fourth version) were summarised with the group of $\mathrm{pN} 2 . R_{0}$ was defined as complete resection to all directions without limit $(0 \mathrm{~mm})$. CRM was not recorded. No central pathological review was performed.

\section{Stratification and randomisation procedures}

Randomisation was performed during a phone call according to an allocation sequence generated by the Institute of Biometrics of the
University of Ulm. Patients were stratified according to the centre, pT (pT1/2 vs pT3/4), and lymph node status ( $\mathrm{pN} 0$ vs $\mathrm{pN} 1$ vs $\mathrm{pN} 2$ ).

\section{Chemotherapy}

At the time of the trial design, systemic adjuvant therapy of rectal cancer was carried out analogous to the recommended standard in colon cancer, consisting of 5-FU and oral levamisol for 12 months (NIH Consensus Conference, 1990). Therapy was scheduled to begin 14 days after surgery. All patients received 5-FU and levamisol. Levamisol $(50 \mathrm{mg})$ was given orally three times on 3 consecutive days every 2 weeks (days 1-3). 5-Fluorouracil $\left(450 \mathrm{mg} \mathrm{m}^{-2}\right)$ was administered as infusion for $60-120 \mathrm{~min}$ on days $1-5$. At 28 days after this loading course, 5 -FU was given once weekly for 48 weeks and, if tolerated well, increased to $500 \mathrm{mg} \mathrm{m}^{-2}$. During irradiation, 5-FU was reduced to $80 \%$. Folinic acid (200 $\mathrm{mg} \mathrm{m}^{-2}$, Rescuvolin, Medac GmbH, Hamburg, Germany) was given as a short infusion (10 $\mathrm{min}$ ) before 5-FU. Interferon- $\alpha$ (Roferon, Roche, Grenzach-Wyhlen, Germany) treatment consisted of $6 \times 10^{6} \mathrm{IU}$ as subcutaneous self-injection $3 \times$ weekly. Training of self-injection was initiated on day 28 .

\section{Radiation}

Radiotherapy consisted of $50.4 \mathrm{~Gy}$ ( $45 \mathrm{~Gy}$ with $5.4 \mathrm{~Gy}$ small volume boost) delivered in fractions of 1.8 Gy $5 \times$ weekly starting 6-8 weeks after surgery and was carried out lying face down and using a three-field technique. The target volume included the primary tumour and its mesentery with vascular supply containing the peri-rectal, pre-sacral, and internal iliac nodes. The upper limit was the L5/S1 junction, the dorsal limit the outer face of the sacrum/coccygis, the ventral limit the inner bone of the os pubis, and the lower limit at least $3 \mathrm{~cm}$ below the anastomosis in case of $\mathrm{AR}$, and including the perineum in case of APR.

\section{Toxicity}

Toxicity was evaluated according to the WHO criteria. Follow-up during adjuvant treatment as well as dose-reduction procedures in case of grade III or IV toxicities were described (Link et al, 2005). Severe toxicities were reported to the German drug authority 'BfArM'.

\section{Follow-up}

Follow-up was performed 4-monthly for 2 years and 6-monthly for 3 years, including history, physical examination, white blood count, liver and renal function, and carcinoembryonic antigen. Computed tomography of the pelvis, abdominal ultrasound, and chest X-ray were performed annually, and colonoscopy biannually. Additional annual follow-up exceeding 5 years was optional.

\section{Statistical analysis and end points}

The primary objective was to improve adjuvant 5-FU chemoradiotherapy. Our hypothesis was that modulation of $5-\mathrm{FU}$ by addition of either FA or INF $\alpha$ may increase overall survival (OS).

For sample size estimation, the following assumptions were made: the 5-year OS rate of 5-FU was estimated to be $58 \%$ (Krook et al, 1991). If the 5-year OS rate for one of the additives is $10 \%$ points higher compared with 5 -FU, the study has $80 \%$ power to detect superiority at a level of significance of $5 \%$ (one-sided), with a sample size of 280 subjects per group. 5-Fluorouracil alone was compared with 5-FU with the addition of FA and INF $\alpha$. Owing to the fact that the INF $\alpha$ arm was closed in 1999 (see Results), a confirmatory comparison was only carried out for 5-FU alone $v s$ 5-FU + FA (log-rank test). 
Primary end point of the study was OS. Overall survival was compared by log-rank testing for 5-FU alone and 5-FU + FA. Secondary end points were recurrence-free survival (RFS), LR, toxicity, and treatment compliance. Overall survival was computed from the start of chemotherapy until death of any cause (events) or until the last observation date (censored observations). Recurrence-free survival was defined as time from the start of chemotherapy until diagnosis of any tumour recurrence or tumour-related death (events) or until death due to other reasons or last observation date (censored observations). Local recurrence was defined as time from the start of chemotherapy to diagnosis of local tumour recurrence (events) or death, last observation date, or sole occurrence of distant metastases (censored observations). Survival curves were generated by the Kaplan-Meier method. Five-year survival rates are shown in \% with 95\% confidence intervals. Toxicity rates were compared between the treatment arms using the $\chi^{2}$ test. Stratified Kaplan-Meier analyses were performed to detect variables influencing LR, RFS, and OS, and compared with the log-rank test. All these tests were used for exploratory data analysis. Statistical analysis was performed using SAS version 9.1 (SAS Institute Inc., Carry, NC, USA).

\section{RESULTS}

\section{Patient and tumour characteristics}

A total of 863 patients from 55 hospitals were enrolled. Of these, 67 $(7.8 \%)$ were regarded as drop-outs (Figure 1). Clinical and pathological characteristics of the remaining 796 patients are summarised in Table 1.

\section{Adjuvant treatment and compliance}

Treatment was started on 29 July 1992 for the first patient and finished on 6 March 2003 for the last patient. All 796 patients

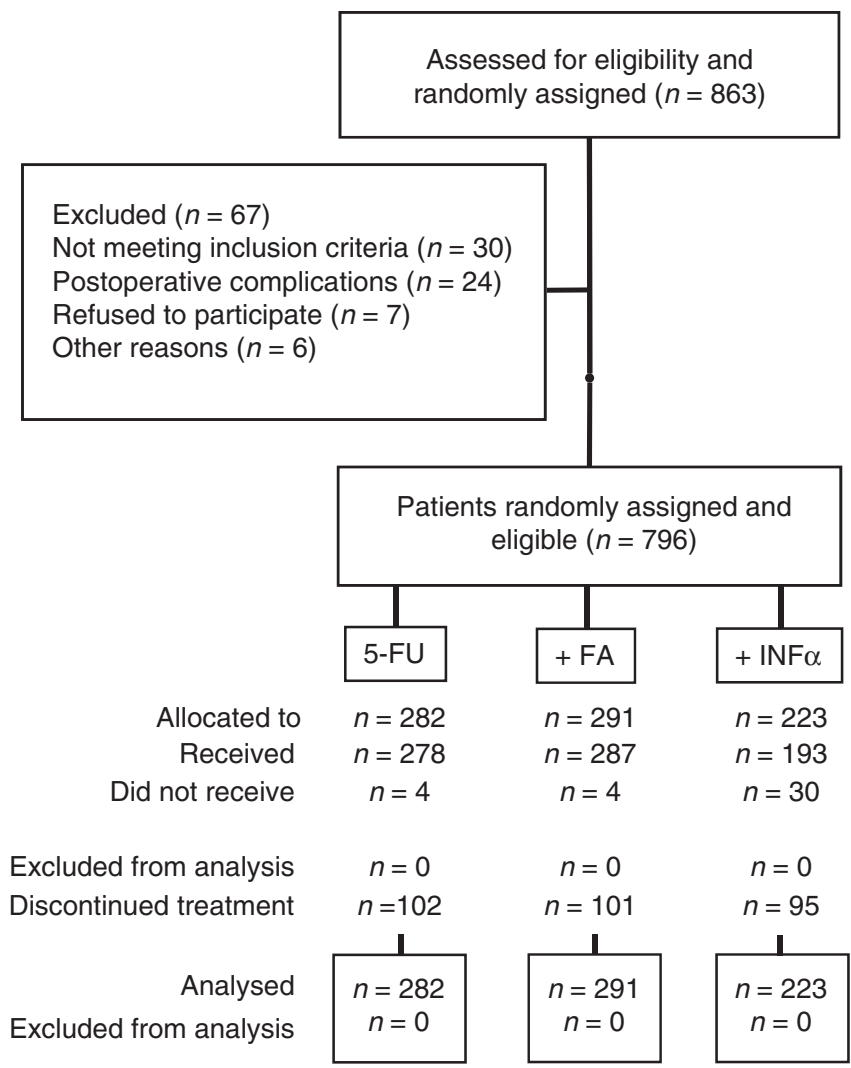

Figure I CONSORT diagram. received 5-FU chemotherapy (Figure 1). Four patients randomised to 5-FU alone received additional FA and four randomised to 5-FU + FA received only 5-FU (Figure 1). Self-injection of INF $\alpha$ was refused by 30 patients (Figure 1). In total, 11 received the 5-FU loading course and discontinued any further adjuvant therapy. In all, 19 continued adjuvant treatment without INF $\alpha$, of these seven received $5-\mathrm{FU}$ alone and 12 asked to receive $5-\mathrm{FU}+\mathrm{FA}$.

The administration of the complete 12-month course of adjuvant chemoradiotherapy was documented for $50.3 \%$ (400 out of 796 ) of the patients, $50.4 \%$ (142 out of 282 ), $53.3 \%$ (155 out of 291), and $46.2 \%$ (103 out of 223) of the 5-FU, 5-FU + FA, and 5 -FU + INF $\alpha$ group, respectively (Figure 1, Table 2). At least 6 months were given to $67.7 \%$ (539 out of 796). Discontinuation was observed in $10.8 \%(n=86)$ within the first, 9.5\% $(n=76)$ within the second, $6.7 \%(n=53)$ within the third, and $10.8 \%$ $(n=86)$ within the fourth quarter. No data about the duration of chemotherapy were available for 95 patients. Reasons for discontinuation of chemotherapy are shown in Table 2 .

For patients discontinuing chemotherapy within the first quarter of treatment $(n=86)$, radiation was not administered in

Table I Clinical and pathological characteristics

\begin{tabular}{|c|c|c|c|c|}
\hline \multirow[b]{2}{*}{$\begin{array}{l}\text { Patients } \\
\text { Number }\end{array}$} & \multicolumn{3}{|c|}{ Treatment } & \multirow[b]{2}{*}{$\begin{array}{c}\text { Total } \\
(N=796)\end{array}$} \\
\hline & $\begin{array}{c}5-F U \\
(N=282)\end{array}$ & $\begin{array}{l}\text { 5-FU+FA } \\
(N=291)\end{array}$ & $\begin{array}{c}\text { 5-FU+IFN } \alpha \\
(N=223)\end{array}$ & \\
\hline \multicolumn{5}{|l|}{ Age (years) } \\
\hline Median & 61.6 & 61.4 & 61.2 & 61.4 \\
\hline Range & $31.5-81.4$ & $23.0-81.4$ & $29.6-86.3$ & $23.0-86.3$ \\
\hline \multicolumn{5}{|l|}{ Sex } \\
\hline Male & 180 & 191 & 140 & 511 \\
\hline Female & 102 & 100 & 83 & 285 \\
\hline \multicolumn{5}{|l|}{ Type of resection ${ }^{a}$} \\
\hline$A R^{b}$ & 135 & 126 & 98 & 359 \\
\hline APR & 60 & 78 & 50 & 188 \\
\hline Unknown & 87 & 87 & 75 & 249 \\
\hline \multicolumn{5}{|l|}{ UICC stage } \\
\hline$\|$ & 93 & 97 & 81 & 271 \\
\hline A T3 No & 85 & 89 & 71 & 245 \\
\hline B T4 No & 8 & 8 & 10 & 26 \\
\hline III & 189 & 194 & 142 & 525 \\
\hline $\mathrm{A} T \mathrm{~T} / 2 \mathrm{NI}$ & 26 & 25 & 20 & 71 \\
\hline B T3/4 NI & 76 & 87 & 64 & 227 \\
\hline $\mathrm{CTI}-4 \mathrm{~N} 2$ & 87 & 82 & 58 & 227 \\
\hline \multicolumn{5}{|l|}{ Tumour depth $(T)$} \\
\hline I & 3 & 2 & 4 & 9 \\
\hline 2 & 33 & 35 & 18 & 86 \\
\hline 3 & 225 & 227 & 182 & 634 \\
\hline 4 & 21 & 27 & 19 & 67 \\
\hline \multicolumn{5}{|l|}{ Lymph nodes (N) } \\
\hline 0 & 93 & 97 & 81 & $27 \mid$ \\
\hline I & 102 & 112 & 84 & 298 \\
\hline 2 & 87 & 82 & 58 & 227 \\
\hline \multicolumn{5}{|l|}{ Grading (G) } \\
\hline $1+2$ & 212 & 219 & 174 & 605 \\
\hline 3 & 55 & 61 & 42 & 158 \\
\hline Unknown & 15 & 11 & 7 & 33 \\
\hline
\end{tabular}

Abbreviations: $\quad A R=$ anterior resections; $\quad A P R=$ abdominoperineal resections; $\mathrm{FA}=$ folinic acid; 5 -FU $=5$-fluorouracil; $\mathrm{IFN} \alpha=$ interferon- $\alpha$; $\mathrm{UICC}=$ International Union Against Cancer. ${ }^{a}$ Type of resection was determined retrospectively. ${ }^{b}$ Including Hartmann procedures (5-FU, $n=3 ; 5-F U+F A, n=3 ; 5-F U+I N F \alpha, n=3$; total, $n=9$ ). 
Table 2 Reasons for treatment discontinuation

\begin{tabular}{|c|c|c|c|c|}
\hline & \multicolumn{3}{|c|}{ Treatment } & \multirow[b]{2}{*}{$\begin{array}{c}\text { Total } \\
(N=796)\end{array}$} \\
\hline & $\begin{array}{c}5-F U \\
(N=282)\end{array}$ & $\begin{array}{l}5-F U+F A \\
(N=29 I)\end{array}$ & $\begin{array}{c}5-F U+I F N \alpha \\
(N=223)\end{array}$ & \\
\hline Patient's demand & 33 & 45 & 32 & 110 \\
\hline Toxicity & 14 & 9 & 23 & 46 \\
\hline Disease progression & 45 & 34 & 29 & 108 \\
\hline Secondary tumour & 2 & । & I & 4 \\
\hline Death & 3 & 3 & 2 & 8 \\
\hline Other reasons & 3 & 4 & 6 & 13 \\
\hline Missing information & 2 & 5 & 2 & 9 \\
\hline Total (in \%) & $102(36)$ & I01 (35) & $95(43)$ & $298(37)$ \\
\hline
\end{tabular}

Abbreviations: FA = folinic acid; 5-FU $=5$-fluorouracil; IFN $\alpha=$ interferon- $\alpha$.

21 patients and was discontinued in six patients, whereas no data on radiation were available in 27 patients.

\section{Toxicity}

Toxicity data were available for 685 patients $(86 \%)$. World Health Organisation III and IV toxicities occurred in $37.5 \%$ (257 out of 685 ) of the patients. Despite the fact that 30 of 223 patients $(13.5 \%)$ never received INF $\alpha$, toxicities occurred in more patients $(58.1 \%)$ receiving 5 -FU + INF $\alpha$ than 5 -FU (31.5\%) and 5-FU + FA (27.7\%) attributable to more frequent haematological, gastrointestinal, and neurological courses $(P<0.001$; Table 3$)$. Toxicity-related abruption ( 23 out of $223,10.3 \%$ ) was also higher in comparison to 5 -FU (14 out of 282, 5.0\%) and 5-FU + FA (nine out of 291, 3.1\%). This prompted the study review committee to close the INF $\alpha$ arm in February 1999.

Three deaths due to treatment-related toxicity were documented. One patient receiving 5-FU immediately died after the loading course owing to severe febrile neutropenia followed by pneumonia. Another patient receiving 5-FU + INF $\alpha$ died in month 7 of treatment owing to diarrhoea with massive dehydration and renal failure. The third patient (5-FU) died 6 months after completing chemoradiotherapy owing to infectious complications caused by fistulas in the pelvis without evidence of LR.

\section{Tumour recurrence}

The median follow-up was 4.9 years (range: $0.0-16.7$ years). In all, 349 recurrences have been reported resulting in a recurrence rate of $43.8 \%$ (Table 4 ). Recurrence was reported in seven patients after 5 years of follow-up.

Local recurrence was reported for 100 patients $(12.6 \%)$, of which 45 patients of this group had both local and distant relapse. Treatment did not influence LR in stage III. In contrast, addition of FA reduced 5 -year LR rate by $55 \%$ in stage II disease compared with 5-FU (Table 5). In stage II, IIIa, IIIb, and IIIc, $11.4 \%$ (31 out of 271 ), $11.3 \%$ ( 8 out of 71 ), $11.9 \%$ (27 out of 227 ), and $15.0 \%$ (34 out of 227) had LR, respectively. Patients with grading $1+2$ and 3 had LR in $11.2 \%$ (68 out of 605 ) and $15.8 \%$ (25 out of 158), respectively, and patients undergoing AR and APR in $11.4 \%$ (41 out of 359 ) and $15.4 \%$ (29 out of 188), respectively. The cumulative frequency of LR with respect to adjuvant treatment in UICC stage II, UICC substage, grading, and resection type are summarised in Table 5 and plotted in Figure 2.

Distant metastases were reported in 284 patients $(35.7 \%)$. The addition of FA tended to increase 5-year RFS in stage II, but not in stage III disease (Table 5). Recurrence-free survival was associated with UICC substage, tumour grading, and resection type (Table 5). Kaplan-Meier curves of RFS are shown in Figure 3.
Table 3 Toxicities WHO $\| I+I V$

\begin{tabular}{|c|c|c|c|c|}
\hline & \multicolumn{3}{|c|}{ Treatment } & \multirow[b]{2}{*}{$\begin{array}{c}\text { Total } \\
(N=796)\end{array}$} \\
\hline & $\begin{array}{c}5-F U \\
(N=282)\end{array}$ & $\begin{array}{l}\text { 5-FU+FA } \\
(N=291)\end{array}$ & $\begin{array}{c}5-F U+I N F \alpha \\
(N=223)\end{array}$ & \\
\hline Toxicity data available $\mathrm{a}^{\mathrm{a}}$ & $N=24 I$ & $N=253$ & $N=191$ & $N=685$ \\
\hline Haematological $^{\mathrm{b}}$ & 13 & 6 & 48 & 67 \\
\hline Nausea/vomiting & 7 & 12 & 20 & 39 \\
\hline Diarrhoea & 38 & 41 & 53 & 132 \\
\hline Fever & I & 3 & 13 & 17 \\
\hline Skin & 18 & 16 & 23 & 57 \\
\hline Neurological & 4 & 6 & 13 & 23 \\
\hline Others ${ }^{c}$ & 12 & 19 & 20 & 51 \\
\hline No cause stated & 73 & 67 & 107 & 247 \\
\hline \multicolumn{5}{|l|}{ Caused by } \\
\hline Chemotherapy & 35 & 31 & 56 & 122 \\
\hline Radiotherapy & 19 & 22 & 7 & 48 \\
\hline Both & 22 & 17 & 48 & 87 \\
\hline $\begin{array}{l}\text { Number of patients } \\
\text { (in \%) }\end{array}$ & $76(32)$ & $70(28)$ & | | | (58) & $257(38)$ \\
\hline
\end{tabular}

Abbreviations: $\mathrm{FA}=$ folinic acid; 5-FU $=5$-fluorouracil; IFN $\alpha=$ interferon- $\alpha$; $\mathrm{WHO}=$ World Health Organisation. ${ }^{a}$ The results of toxicity were based on the analysis of 685 patients for whom toxicity data were available. ${ }^{b}$ Number of documented toxicities $>$ WHO II. Including obstipation and infections, as well as renal, pulmonal, and cardiac toxicity. ${ }^{\mathrm{d}}$ Total number of patients affected by any toxicity $>\mathrm{WHO} \|$.

Table 4 Localisation and frequency of tumour recurrence

\begin{tabular}{|c|c|c|c|c|}
\hline & \multicolumn{3}{|c|}{ Treatment } & \multirow[b]{2}{*}{$\begin{array}{c}\text { Total } \\
(N=796)\end{array}$} \\
\hline & $\begin{array}{c}5-F U \\
(N=282)\end{array}$ & $\begin{array}{l}5-F U+F A \\
(N=29 I)\end{array}$ & $\begin{array}{c}5-F U+I N F \alpha \\
(N=223)\end{array}$ & \\
\hline Total number of patients & 129 & 123 & 97 & 349 \\
\hline Recurrence rate (in \%) & 45.7 & 42.3 & 43.5 & 43.8 \\
\hline Local recurrence (only) (in \%) & $21(7.4)$ & $16(5.5)$ & $18(8.1)$ & $55(6.9)$ \\
\hline $\begin{array}{l}\text { Local and distant recurrence } \\
\text { (in \%) }\end{array}$ & $18(6.4)$ & $15(5.2)$ & $12(5.4)$ & $45(5.7)$ \\
\hline $\begin{array}{l}\text { Distant recurrence (only) } \\
\text { (in \%) }\end{array}$ & $88(31.2)$ & $88(30.2)$ & $63(28.3)$ & $239(30.0)$ \\
\hline Unknown localisation (in \%) & $2(0.7)$ & $4(1.4)$ & $4(1.8)$ & $10(1.3)$ \\
\hline \multicolumn{5}{|l|}{ Distant metastases (events) ${ }^{\mathrm{a}}$} \\
\hline Liver & 60 & 54 & 42 & 156 \\
\hline Lung & 41 & 35 & 25 & $10 \mid$ \\
\hline Peritoneum & 16 & 8 & 8 & 32 \\
\hline Bone & 2 & | | & 4 & 17 \\
\hline Other locations & 23 & 22 & 17 & 62 \\
\hline
\end{tabular}

Abbreviations: $F A=$ folinic acid; 5-FU $=5$-fluorouracil; IFN $\alpha=$ interferon- $\alpha$. ${ }^{\mathrm{a}}$ Owing to the fact that some patients showed more than one location of distant metastases, the total number of distant metastases is higher than the patient number.

\section{Survival}

As of November 2009, 335 patients $(42.1 \%)$ died, $43.3 \%$ of the patients (122 out of 282 ) receiving 5 -FU, $40.9 \%$ of the patients (119 out of 291 ) receiving $5-\mathrm{FU}+\mathrm{FA}$, and $42.2 \%$ of the patients (94 out of 223) receiving 5-FU + INF $\alpha$. Disease-specific (disease-related) deaths occurred in $36.2 \%$ of the patients with 5 -FU (102 out of 282 ), in $33.7 \%$ of the patients with $5-\mathrm{FU}+\mathrm{FA}$ (98 out of 291 ), and in $33.6 \%$ of the patients receiving with $5-\mathrm{FU}+\mathrm{INF} \alpha$ (75 out of $223)$, combining to a total disease-specific death rate of $82.1 \%(275$ out of 335$)$. A total of 43 patients (12.8\%) died of other reasons, including the three patients with treatment-related toxicity, whereas the cause of death was unknown in 17 patients. 
Table 5 Five-year rates of LR, RFS and OS by risk group

Five-year rates

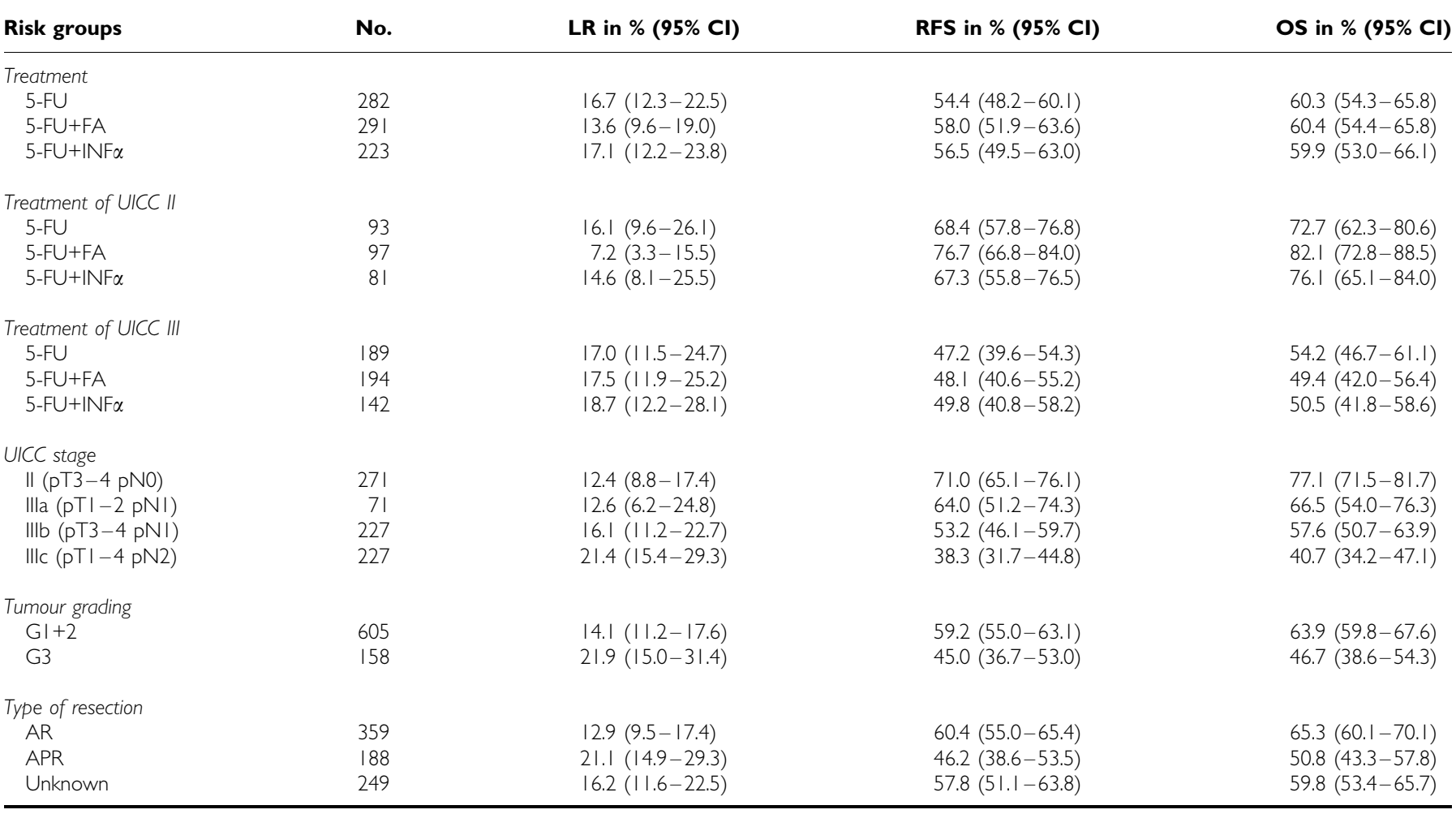

Abbreviations: $A R=$ anterior resections, including Hartmann procedures $(n=9 ; \quad A P R=$ abdominoperineal resections; $C l=$ confidence interval; $F A=$ folinic acid; 5-FU = 5-fluorouracil; IFN $\alpha=$ interferon- $\alpha$; $\mathrm{RR}=$ local recurrence; OS = overall survival; RFS = recurrence-free survival; UICC = International Union Against Cancer.

A
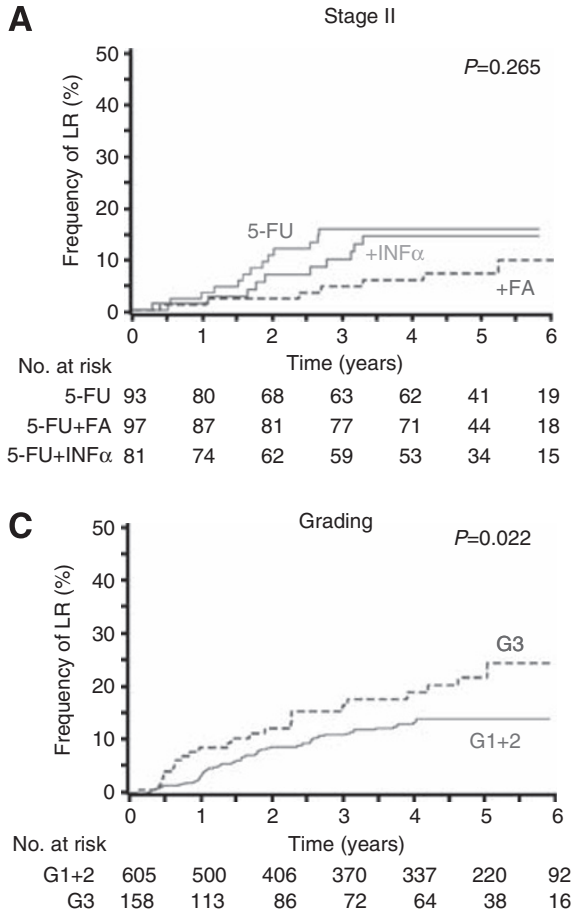
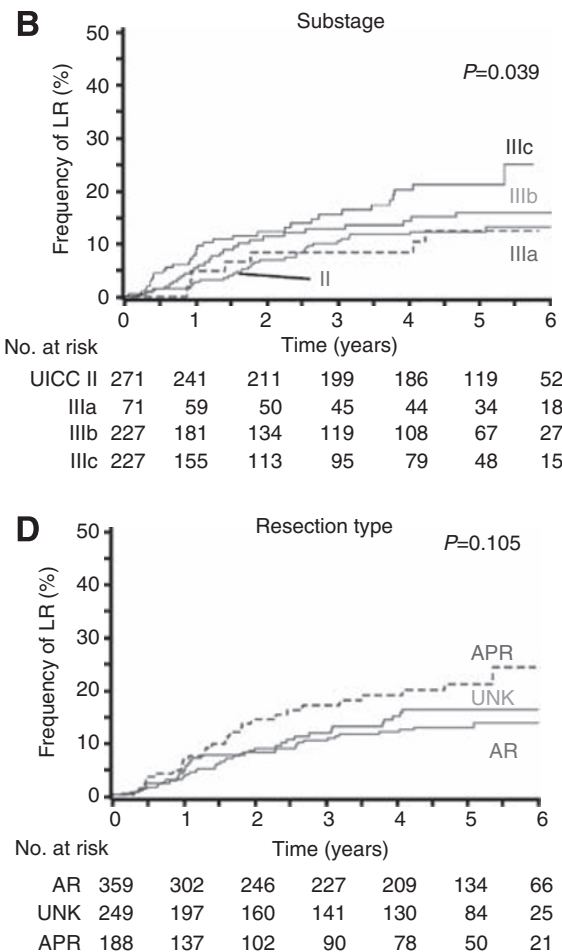

Figure 2 Cumulative frequency of local recurrence (LR): (A) LR in UICC stage II (pT3/4pN0) according to treatment; (B) LR according to UICC stage II (pT3/4pN0), and substages IIla (pTI/2pNI), IIlb (pT3/4pNI), and IIlc (pTI-4pN2); (C) LR according to tumour grading; and (D) LR according to the type of resection: anterior resection (AR), abdominoperineal resection (APR), and resection type unknown (UNK). AR included nine Hartmann procedures. 

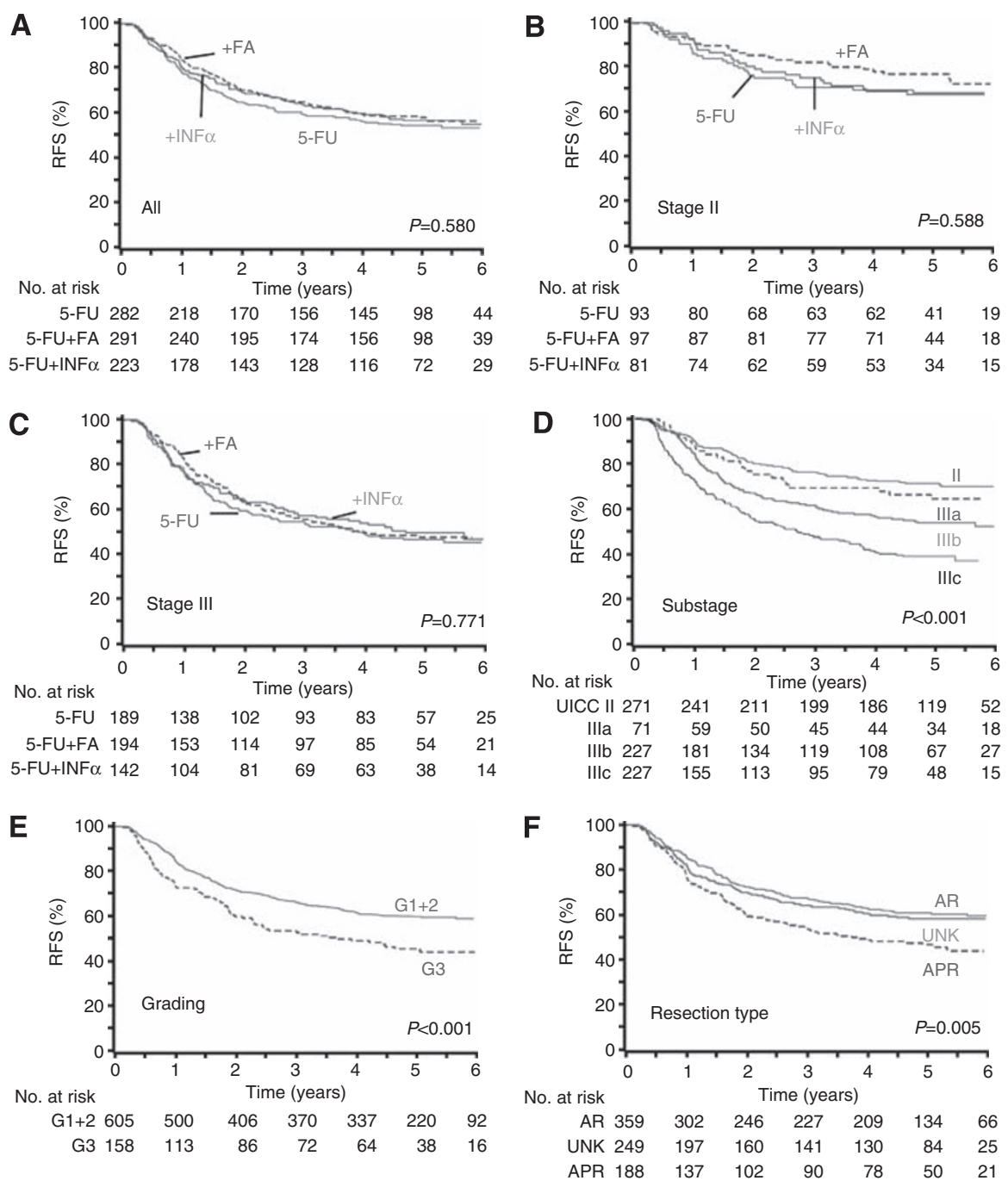

Figure 3 Recurrence-free survival according to: $(\mathbf{A})$ treatment for all stages; (B) treatment of stage II (pT3/4pN0); (C) treatment of stage III (pTI-4pNpos); (D) UICC stage II (pT3/4pN0), and substages IIla (pTI/2pNI), IIIb (pT3/4pNI), and IIIc (pTI-4pN2); (E) tumour grading (GI + 2 vs G3); and $(\mathbf{F})$ type of resection: anterior resection (AR), abdominoperineal resection (APR), and resection type unknown (UNK). AR included nine Hartmann procedures.

5 -Fluorouracil + FA tended to a superior OS rate after 3 years (78.3\%) compared with 5-FU (72.8\%) and 5-FU + INF $\alpha(70.9 \%)$. However, no differences were seen after 5 years (Table 5, Figure 4A). The addition of FA tended to an improved OS in stage II, whereas no effects were observed in stage III disease (Table 5, Figure 4B+C). Overall survival was influenced by UICC substage, tumour grading, and resection type (Table 5, Figure $4 \mathrm{D}-\mathrm{F})$.

\section{DISCUSSION}

Adjuvant chemoradiotherapy of locally advanced rectal cancer was established based on three trials, including 104 (Gastrointestinal Tumor Study Group, 1985), 204 (Krook et al, 1991), and 555 patients (Fisher et al, 1988). Our trial design was based on the results of these studies not allowing a 'surgery-only' arm. The main problem of the study was patient recruitment. Nevertheless, duration and time of recruitment are comparable to other European rectal cancer trials launched in the early 1990s (Sauer et al, 2004; Bosset et al, 2006; Gérard et al, 2006). The German ARO-CAO-AIO-94 study compared pre- $v s$ postoperative chemoradiotherapy (Sauer et al, 2004), and the two French trials compared pre-operative radiotherapy with chemoradiotherapy with or without postoperative chemotherapy (Bosset et al, 2006; Gérard et al, 2006). Two trials initiated in the United States in the early 1990s comparing pre-operative chemoradiotherapy with standard, postoperative chemoradiotherapy by the RTOG (trial 94-01) and the National Surgical Adjuvant Breast and Bowel Project (protocol R-03) were closed prematurely owing to low enrolment (Hyams et al, 1997). Trials starting in the later 1990s compared pre-operative short-course radiotherapy vs TME surgery alone (Peeters et al, 2007) or vs postoperative selective chemoradiotherapy (Sebag-Montefiore et al, 2009) or pre-operative short-course radiotherapy $v s$ chemoradiotherapy applying TME surgery (Bujko et al, 2006). With the exception of the Swedish Rectal Cancer Trial (1997), rectal cancer trials involving multimodal treatment revealed improvement of local control without benefit for prognosis (Sauer et al, 2004; Bosset et al, 2006; Bujko et al, 2006; Gérard et al, 2006; Peeters et al, 2007; Sebag-Montefiore et al, 2009).

In the area of TME surgery, prognosis of patients with locally advanced rectal cancer primarily depends on the occurrence of distant metastases. No study could show an improvement of 
A

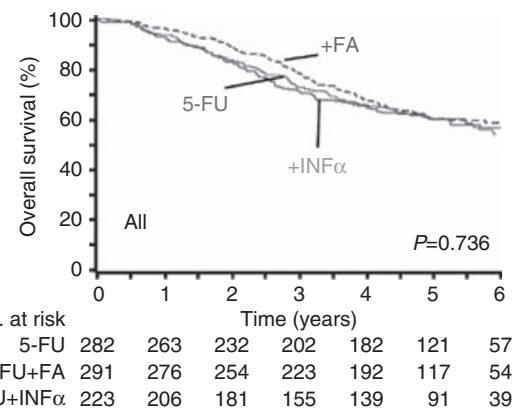

C

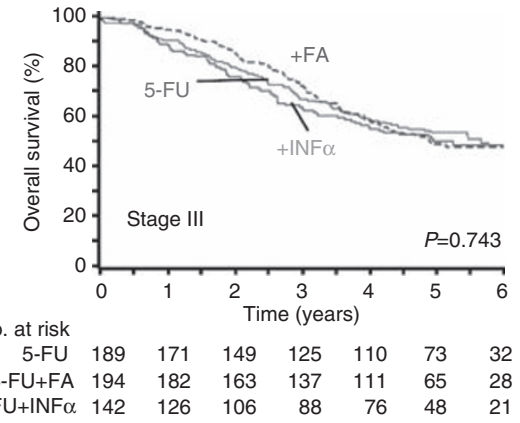

E

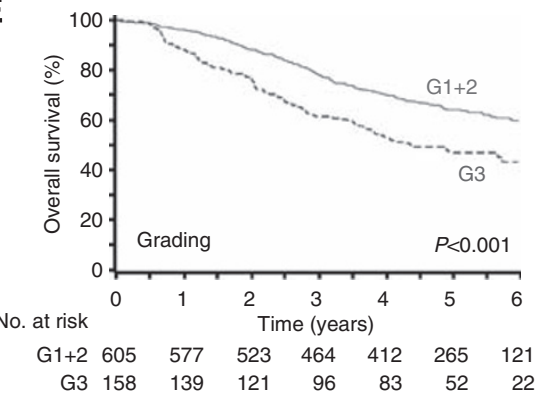

B
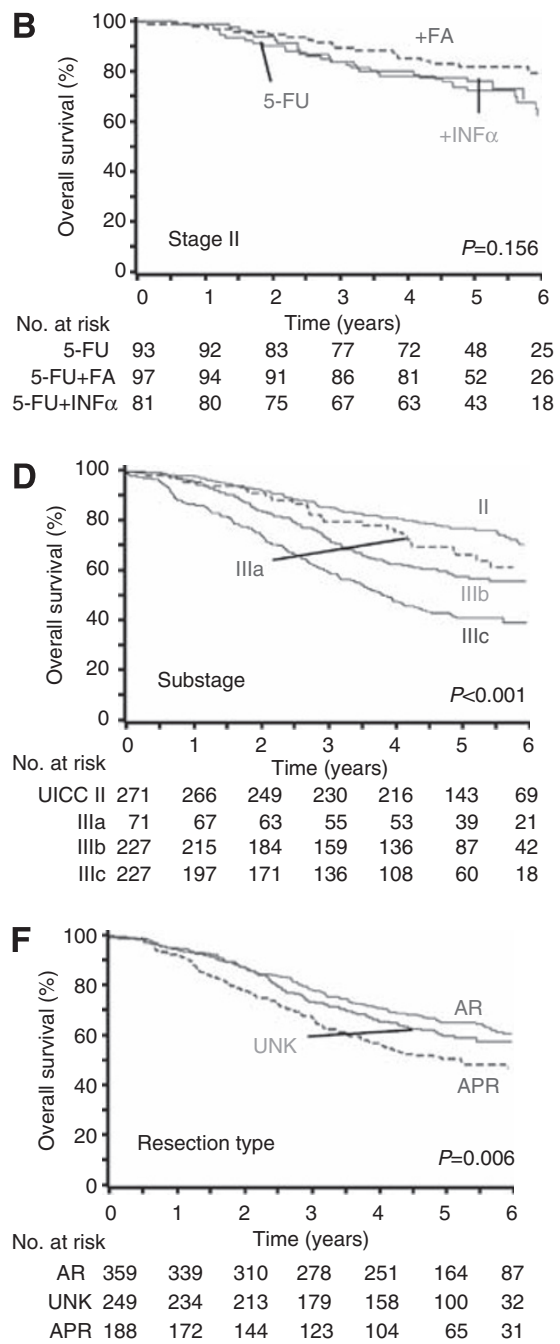

Figure 4 Overall survival according to: $(\mathbf{A})$ treatment for all stages. 5-Fluorouracil vs 5-FU + FA: log-rank test, $P=0.46$ I; $(\mathbf{B})$ treatment of stage II (pT3/4pN0); (C) treatment of stage III (pTI -4pNpos); (D) UICC stage II (pT3/4pN0), and substages IIla (pTI/2pNI), IIIb (pT3/4pN I), and IIIc (pTI -4pN2); (E) tumour grading (GI +2 vs G3); and (F) type of resection: anterior resection (AR), abdominoperineal resection (APR), and resection type unknown (UNK). AR included nine Hartmann procedures.

prognosis in multimodal treatment of rectal cancer in comparison to standard 5-FU (de Gramont and Haller, 2008). Our study aimed to improve prognosis by modulating 5 -FU by either addition of FA or INF $\alpha$. In parallel, we carried out an equivalent study in colon cancer, except radiation including 855 patients (Link et al, 2005). Similar to our colon cancer study, INF $\alpha$ increased toxicity in rectal cancer, too, without survival benefit. The effectiveness of combining 5-FU with FA in colon cancer is generally accepted and was confirmed in our colon trial increasing the 5-year OS rate from 61 to $72 \%$ using the same drug administration and protocol design (Link et al, 2005). More than $90 \%$ of patients with stage III colon cancer were included. In this study, not a trend of benefit was observed in node-positive (stage III) rectal cancer. However, there seemed to be a benefit of FA addition in stage II cutting LR rate by half and enhancing OS by almost 10 points of percentage $(82.1 \mathrm{vs}$ $72.7 \%$ ) compared with 5-FU. A pooled analysis of Scandinavian patients comparing surgery only with postoperative adjuvant 5-FU-based chemotherapy in rectal cancer showed a similar trend. Patients with stage II seemed to benefit, whereas there was no effect of adjuvant treatment compared with surgery alone in stage III (Glimelius et al, 2005). A subgroup analysis of EORTC Trial 22921 comparing pre-operative (chemo)radiotherapy with or without postoperative chemotherapy in a $2 \times 2$ factorial design revealed that responders (ypT0-2) seemed to benefit from adjuvant chemotherapy in contrast to non-responders (ypT3-4) (Collette et al, 2007). These observations suggest that especially non-metastasised and radiosensitive tumours may benefit from adjuvant 5-FU treatment with the addition of FA, whereas nonresponding and lymph node-positive tumour may not.

On the basis of this observation in stage II of our study that the reduction of LR was associated with an improvement of RFS and OS and the ineffectiveness of FA in stage III, some assumptions can be made. First, the addition of FA $\left(200 \mathrm{mg} \mathrm{m}^{-2}\right)$ may enhance the effect of 5-FU as a radiosensitiser to improve local control. Second, the addition of FA may be ineffective to avoid recurrence at a stage of rectal cancer at which metastatic spread is already present in lymph nodes. Third, chemosensitivity of rectal cancer may differ from that of colon cancer. This is supported by comparisons with colon cancer trials (Glimelius et al, 2005; Link et $a l, 2005)$ and other trials failing to show an improvement of adjuvant 5-FU monotherapy in rectal cancer (QUASAR Collaborative Group, 2000; Tepper et al, 2002; Dahl et al, 2009). In addition, new combinations, which also showed effectiveness in colon cancer treatment, failed to show any benefit in rectal cancer so far (Glynne-Jones et al, 2010; Weiss et al, 2010). The German CAO/ARO/AIO-04 rectal cancer trial comparing standard 5-FU 
neoadjuvant and adjuvant treatment with an intensified protocol, including oxaliplatin in the pre- and postoperative setting (Rödel and Sauer, 2007), was recently closed for recruitment. However, no differences in the rate of pathological complete response to neoadjuvant therapy as a surrogate marker for overall prognosis were reported so far. The effects on distant metastasis and final outcome render evaluation after sufficient follow-up time in a few years for this and other ongoing European and United States trials.

The duration of adjuvant chemotherapy in our trial was 12 months. All patients received oral levamisol. Presently, a duration of 6-8 months is recommended with omission of levamisol. These recommendations are mainly based on results obtained from colon cancer trials showing no difference in outcome omitting levamisol and shortening the duration of chemotherapy. The four-arm INT-0089 trial, including patients with high-risk stage II and stage III colon cancer, revealed no significant difference between adjuvant therapy with 5-FU + FA (low dose, $20 \mathrm{mg} \mathrm{m}^{-2}$ or high dose, $500 \mathrm{mg} \mathrm{m}^{-2}$ ) for 7-8 months and the 12-month 5-FU + LEV standard and an increase in the 5year OS rate from $63 \%$ (12-month 5 -FU + LEV) to $67 \%$ for 7-8 months 5-FU + LEV + FA (low dose) (Haller et al, 1998). The NCCTG/NCIC trial (O'Connell et al, 1998), including 915 similarly staged patients, displayed 5 -year OS rates of $64 \%$ for 12 -month 5 -FU + LEV, of $61 \%$ for 12 -month 5 -FU + LEV + FA, of $69 \%$ for 6 -month treatment with 5-FU + FA, and of 59\% for 6-month treatment with 5-FU + LEV. Except the two 6-month treatment arms, the differences between the treatment arms were not significant. On the basis of the results, a 6- to 8-month adjuvant treatment seemed to be equivalent to a 12 -month 5 -FU + LEV treatment after the addition of FA. Furthermore, omission of LEV seemed to be justified without compromising the survival benefit in colon cancer.

Attention has be drawn to a variety of additional anatomical and surgical factors influencing the outcome of rectal cancer. The tumour distance from the anal verge seems of great importance as shown in our study as well. As a result, patients with low rectal cancer undergoing an APR had a 63\% higher LR rate than patients undergoing an $\mathrm{AR}$ in our and other studies (Wibe et al, 2002; den Dulk et al, 2009). Localisation of the tumour in the rectum may be another essential prognostic factor. To achieve a complete resection with negative circumferential resection margins, it is important that the tumour is covered with mesorectal fatty tissue (Heald et al, 2004; Nagtegaal and Quirke, 2008). The mesorectum is thinned out in the lower parts, especially in the front (Heald et al, 2004). Moreover, the individual surgeon may be also another important prognosticator (Martling et al, 2000). All these factors and the combination with radiotherapy may dilute the positive effect of 5-FU modulation by FA in rectal cancer, which seems so obvious in colon cancer.

In summary, we could not show a benefit of modulating 5-FU with either FA or INF $\alpha$ in adjuvant chemoradiotherapy of locally

\section{REFERENCES}

Allen WL, Johnston PG (2005) Role of genomic markers in colorectal cancer treatment. J Clin Oncol 23: 4545-4552

André T, Boni C, Navarro M, Tabernero J, Hickish T, Topham C, Bonetti A, Clingan P, Bridgewater J, Rivera F, de Gramont A (2009) Improved overall survival with oxaliplatin, fluorouracil, and leucovorin as adjuvant treatment in stage II or III colon cancer in the MOSAIC trial. J Clin Oncol 27: $3109-3116$

Bosset JF, Collette L, Calais G, Mineur L, Maingon P, Radosevic-Jelic L, Daban A, Bardet E, Beny A, Ollier JC, EORTC Radiotherapy Group Trial 22921 (2006) Chemotherapy with preoperative radiotherapy in rectal cancer. N Engl J Med 355: 1114-1123

Bujko K, Nowacki MP, Nasierowska-Guttmejer A, Michalski W, Bebenek M, Kryj M (2006) Long-term results of a randomized trial comparing advanced rectal cancer despite a tendency in improved 3-year survival. Nevertheless, our results point out to a potential longterm benefit of FA in stage II disease. Therefore, in our opinion, this protocol can be recommended for adjuvant chemoradiotherapy of stage II disease. Owing to a reduction in LR, we conclude that this effect may be due to increased efficacy of chemoradiotherapy. In the future, this protocol may be recommended for patients not having received neoadjuvant treatment being diagnosed with a pT3c/dpN0 tumour or with a small CRM $(<2 \mathrm{~mm})$. Patients with $\mathrm{pT} 3 \mathrm{a} / \mathrm{bpN} 0$ or a large CRM $(>2 \mathrm{~mm})$ may undergo observation. The effect of adjuvant treatment, even 5-FU monotherapy, after neoadjuvant chemoradiotherapy and high quality of surgery renders re-evaluation.

Our study further confirmed important prognostic factors like grading, type of resection, and UICC substage (Gunderson et al, 2002). In view of the efficacy of our FA protocol in colon cancer, we further conclude that rectal cancer may be a separate entity with different chemosensitivity. This is supported by numerous observations of differences in genetic alterations or target gene expression like microsatellite instability or expression of thymidylate synthase (Kornmann et al, 2003; Allen and Johnston, 2005; Wilson et al, 2007).

As all attempts to optimise and develop new combinations for chemotherapy of rectal cancer have failed so far and no really promising additional multimodal treatment options are under evaluation at present, it seems important to focus on approaches minimising over-treatment. For example, accurate pre-therapeutic MRI-based local staging may better identify patients that can profit from neoadjuvant treatment based on the CRM. In conjunction with additional individual prognostic markers like grading, tumour location, and tumour substaging, this may help to reduce the need for multimodal strategies. Future trials should therefore aim at optimising available multimodal options for high-risk subgroups, thereby reducing the overall number of patients undergoing multimodal treatment. A recent survey asking laypersons about their preferred treatment choices further would support this strategy (Kornmann et al, 2008). This may save toxicity and increase quality of life without hampering prognosis. These efforts may eventually help to individualise and optimise multimodal treatment of locally advanced rectal cancer in the future.

\section{ACKNOWLEDGEMENTS}

We would like to acknowledge all participants and U Kemmer and $S$ Sander for data documentation and analysis. This trial was financially supported by the Cancer Center of the University of Ulm, Medac GmbH (Hamburg), and Roche (Grenzach-Wyhlen), Germany. preoperative short-course radiotherapy with preoperative conventionally fractionated chemoradiation for rectal cancer. Br J Surg 93: 1215-1223

Collette L, Bosset JF, den Dulk M, Nguyen F, Mineur L, Maingon P, Radosevic-Jelic L, Piérart M, Calais G, European Organisation for Research and Treatment of Cancer Radiation Oncology Group (2007) Patients with curative resection of cT3-4 rectal cancer after preoperative radiotherapy or radiochemotherapy: does anybody benefit from adjuvant fluorouracil-based chemotherapy? A trial of the European Organisation for Research and Treatment of Cancer Radiation Oncology Group. J Clin Oncol 25: 4379-4386

Corfu-A Study Group (1995) Phase III randomized study of two fluorouracil combinations with either interferon alfa-2a or leucovorin for advanced colorectal cancer. J Clin Oncol 13: 921-928 
Dahl O, Fluge Ø, Carlsen E, Wiig JN, Myrvold HE, Vonen B, Podhorny N, Bjerkeset O, Eide TJ, Halvorsen TB, Tveit KM, Norwegian Gastrointestinal Cancer Group (2009) Final results of a randomised phase III study on adjuvant chemotherapy with $5 \mathrm{FU}$ and levamisol in colon and rectum cancer stage II and III by the Norwegian Gastrointestinal Cancer Group. Acta Oncol 48: 368-376

de Gramont A, Haller DG (2008) Accomplishments in 2007 in the adjuvant treatment of colorectal cancer. Gastrointest Cancer Res 2(3, Suppl): S2-S6

den Dulk M, Putter H, Collette L, Marijnen CA, Folkesson J, Bosset JF, Rödel C, Bujko K, Påhlman L, van de Velde CJ (2009) The abdominoperineal resection itself is associated with an adverse outcome: the European experience based on a pooled analysis of five European randomised clinical trials on rectal cancer. Eur J Cancer 45: $1175-1183$

Fisher B, Wolmark N, Rockette H, Redmond C, Deutsch M, Wickerham DL, Fisher ER, Caplan R, Jones J, Lerner H (1988) Postoperative adjuvant chemotherapy or radiation therapy for rectal cancer: results from NSABP protocol R-01. J Natl Cancer Inst 80: 21 - 29

Gastrointestinal Tumor Study Group (1985) Prolongation of the diseasefree interval in surgically treated rectal carcinoma. $N$ Engl J Med 312: $1465-1472$

Gérard JP, Conroy T, Bonnetain F, Bouché O, Chapet O, Closon-Dejardin MT, Untereiner M, Leduc B, Francois E, Maurel J, Seitz JF, Buecher B, Mackiewicz R, Ducreux M, Bedenne L (2006) Preoperative radiotherapy with or without concurrent fluorouracil and leucovorin in T3-4 rectal cancers: results of FFCD 9203. J Clin Oncol 24: 4620-4625

Glimelius B, Dahl O, Cedermark B, Jakobsen A, Bentzen SM, Starkhammar H, Grönberg H, Hultborn R, Albertsson $M$, Påhlman L, Tveit KM, Nordic Gastrointestinal Tumour Adjuvant Therapy Group (2005) Adjuvant chemotherapy in colorectal cancer: a joint analysis of randomised trials by the Nordic Gastrointestinal Tumour Adjuvant Therapy Group. Acta Oncol 44: 904-912

Glynne-Jones R, Mawdsley S, Harrison M (2010) Cetuximab and chemoradiation for rectal cancer - is the water getting muddy? Acta Oncol 49: 278-286

Gunderson LL, Sargent DJ, Tepper JE, O'Connell MJ, Allmer C, Smalley SR, Martenson JA, Haller DG, Mayer RJ, Rich TA, Ajani JA, Macdonald JS, Goldberg RM (2002) Impact of T and N substage on survival and disease relapse in adjuvant rectal cancer: a pooled analysis. Int J Radiat Oncol Biol Phys 54: 386-396

Haller DG, Catalano PJ, MacDonald JS (1998) Fluorouracil (FU), leucovorin (LV) and levamisole (LEV) adjuvant therapy for colon cancer: five year final report of INT-0089. Proc Am Soc Clin Oncol 17: 256

Haller DG, Catalano PJ, Macdonald JS, O’Rourke MA, Frontiera MS, Jackson DV, Mayer RJ (2005) Phase III study of fluorouracil, leucovorin, and levamisole in high-risk stage II and III colon cancer: final report of Intergroup 0089. J Clin Oncol 23: 8671-8678

Heald RJ, Moran BJ, Brown G, Daniels IR (2004) Optimal total mesorectal excision for rectal cancer is by dissection in front of Denonvilliers' fascia. Br J Surg 91: $121-123$

Herfahrt C, Schlag P (1991) Richtlinien Zur Operativen Therapie Maligner Tumoren. Karl Demeter Verlag: Stuttgart

Hyams DM, Mamounas EP, Petrelli N, Rockette H, Jones J, Wieand HS, Deutsch M, Wickerham L, Fisher B, Wolmark N (1997) A clinical trial to evaluate the worth of preoperative multimodality therapy in patients with operable carcinoma of the rectum: a progress report of National Surgical Breast and Bowel Project Protocol R-03. Dis Colon Rectum 40: $131-139$

International Multicentre Pooled Analysis of Colon Cancer Trials (IMPACT) investigators (1995) Efficacy of adjuvant fluorouracil and folinic acid in colon cancer. Lancet 345: 939-944

Kornmann M, Henne-Bruns D, Porzsolt F (2008) Neoadjuvant treatment of rectal carcinoma: assessment of health care services by physicians and lay persons. J Clin Oncol 26: 4866-4868

Kornmann M, Schwabe W, Sander S, Kron M, Sträter J, Polat S, Kettner E, Weiser HF, Baumann W, Schramm H, Häusler P, Ott K, Behnke D, Staib L, Beger HG, Link KH (2003) Thymidylate synthase and dihydropyrimidine dehydrogenase mRNA expression levels: predictors for survival in colorectal cancer patients receiving adjuvant 5-fluorouracil. Clin Cancer Res 9: 4116-4124

Krook JE, Moertel CG, Gunderson LL, Wieand HS, Collins RT, Beart RW, Kubista TP, Poon MA, Meyers WC, Mailliard JA (1991) Effective surgical adjuvant therapy for high-risk rectal carcinoma. $N$ Engl J Med 324: $709-715$
Kuebler JP, Wieand HS, O'Connell MJ, Smith RE, Colangelo LH, Yothers G, Petrelli NJ, Findlay MP, Seay TE, Atkins JN, Zapas JL, Goodwin JW, Fehrenbacher L, Ramanathan RK, Conley BA, Flynn PJ, Soori G, Colman LK, Levine EA, Lanier KS, Wolmark N (2007) Oxaliplatin combined with weekly bolus fluorouracil and leucovorin as surgical adjuvant chemotherapy for stage II and III colon cancer: results from NSABP C-7. J Clin Oncol 25: 2198-2204

Link KH, Kornmann M, Staib L, Redenbacher M, Kron M, Beger HG, Study Group Oncology of Gastrointestinal Tumors (2005) Increase of survival benefit in advanced resectable colon cancer by extent of adjuvant treatment: results of a randomized trial comparing modulation of 5-FU+levamisole with folinic acid or with interferon-alpha. Ann Surg 242: $178-187$

Makower D, Wadler S (1999) Interferons as biomodulators of fluoropyrimidines in the treatment of colorectal cancer. Semin Oncol 26: 663-671

Martling AL, Holm T, Rutqvist LE, Moran BJ, Heald RJ, Cedermark B (2000) Effect of a surgical training programme on outcome of rectal cancer in the County of Stockholm. Stockholm Colorectal Cancer Study Group, Basingstoke Bowel Cancer Research Project. Lancet 356: 93-96

Nagtegaal ID, Quirke P (2008) What is the role for the circumferential margin in the modern treatment of rectal cancer? J Clin Oncol 26: $303-312$

NIH Consensus Conference (1990) Adjuvant therapy for patients with colon and rectal cancer. JAMA 264: 1444-1450

O'Connell MJ, Laurie JA, Kahn M, Fitzgibbons Jr RJ, Erlichman C, Shepherd L, Moertel CG, Kocha WI, Pazdur R, Wieand HS, Rubin J, Vukov AM, Donohue JH, Krook JE, Figueredo A (1998) Prospectively randomized trial of postoperative adjuvant chemotherapy in patients with high-risk colon cancer. J Clin Oncol 16: 295-300

Peeters KC, Marijnen CA, Nagtegaal ID, Kranenbarg EK, Putter H, Wiggers T, Rutten H, Pahlman L, Glimelius B, Leer JW, van de Velde CJ, Dutch Colorectal Cancer Group (2007) The TME trial after a median follow-up of 6 years: increased local control but no survival benefit in irradiated patients with resectable rectal carcinoma. Ann Surg 246: $693-701$

Porschen R, Bermann A, Löffler T, Haack G, Rettig K, Anger Y, Strohmeyer G, Arbeitsgemeinschaft Gastrointestinale Onkologie (2001) Fluorouracil plus leucovorin as effective adjuvant chemotherapy in curatively resected stage III colon cancer results of the trial adjCCA-01. J Clin Oncol 19: $1787-1794$

QUASAR Collaborative Group (2000) Comparison of fluorouracil with additional levamisole, higher-dose folinic acid, or both, as adjuvant chemotherapy for colorectal cancer: a randomised trial. Lancet 355: $1588-1596$

Rödel C, Sauer R (2007) Integration of novel agents into combinedmodality treatment for rectal cancer patients. Strahlenther Onkol 183: $227-235$

Sauer R, Becker H, Hohenberger W, Rödel C, Wittekind C, Fietkau R, Martus P, Tschmelitsch J, Hager E, Hess CF, Karstens JH, Liersch T, Schmidberger H, Raab R, German Rectal Cancer Study Group (2004) Preoperative versus postoperative chemoradiotherapy for rectal cancer. N Engl J Med 351: 1731 - 1740

Sebag-Montefiore D, Stephens RJ, Steele R, Monson J, Grieve R, Khanna S, Quirke P, Couture J, de Metz C, Myint AS, Bessell E, Griffiths G, Thompson LC, Parmar M (2009) Preoperative radiotherapy versus selective postoperative chemoradiotherapy in patients with rectal cancer (MRC CR07 and NCIC-CTG C016): a multicentre, randomised trial. Lancet 373: $811-820$

Slaton JW, Perrotte P, Inoue K, Dinney CP, Fidler IJ (1999) Interferonalpha-mediated down-regulation of angiogenesis-related genes and therapy of bladder cancer are dependent on optimization of biological dose and schedule. Clin Cancer Res 5: 2726-2734

Swedish Rectal Cancer Trial (1997) Improved survival with preoperative radiotherapy in resectable rectal cancer. $N$ Engl J Med 336: $980-987$

Tepper JE, O'Connell $\mathrm{M}$, Niedzwiecki D, Hollis DR, Benson III AB, Cummings B, Gunderson LL, Macdonald JS, Martenson JA, Mayer RJ (2002) Adjuvant therapy in rectal cancer: analysis of stage, sex, and local control - final report of Intergroup 0114. J Clin Oncol 20: 1744-1750

Van Triest B, Pinedo HM, Giaccone G, Peters GJ (2000) Downstream molecular determinants of response to 5-fluorouracil and antifolate thymidylate synthase inhibitors. Ann Oncol 11: 385-391

Weiss C, Arnold D, Dellas K, Liersch T, Hipp M, Fietkau R, Sauer R, Hinke A, Rödel C (2010) Preoperative radiotherapy of advanced rectal cancer with capecitabine and oxaliplatin with or without cetuximab: 
a pooled analysis of three prospective phase I-II trials. Int J Radiat Oncol Biol Phys 8: 194-199

Weiss J, Moghanaki D, Plastaras JP, Haller DG (2009) Improved patient and regimen selection in locally advanced rectal cancer: who, how, and what next? Clin Colorectal Cancer 8: 194-199

Wibe A, Møller B, Norstein J, Carlsen E, Wiig JN, Heald RJ, Langmark F, Myrvold HE, Søreide O, Norwegian Rectal Cancer Group (2002) A national strategic change in treatment policy for rectal cancer implementation of total mesorectal excision as routine treatment in Norway. A national audit. Dis Colon Rectum 45: 857-866

Wilson PM, Ladner RD, Lenz HJ (2007) Predictive and prognostic markers in colorectal cancer. Gastrointest Cancer Res 1: $237-246$

Wolmark N, Wieand HS, Hyams DM, Colangelo L, Dimitrov NV, Romond EH, Wexler M, Prager D, Cruz Jr AB, Gordon PH, Petrelli NJ, Deutsch M, Mamounas E, Wickerham DL, Fisher ER, Rockette H, Fisher B (2000) Randomized trial of postoperative adjuvant chemotherapy with or without radiotherapy for carcinoma of the rectum: National Surgical Adjuvant Breast and Bowel Project Protocol R-02. J Natl Cancer Inst 92: 388-396

\section{Appendix}

The following investigators participated in the trial and recruited at least 10 patients: E Kettner, Department of Medicine, Städtisches Klinikum, Magdeburg; H Schramm, Department of Surgery, Waldklinikum, Gera; W Baumann, Department of Surgery, Klinik am Eichert, Göppingen; T Liersch, Department of Surgical Oncology, University of Göttingen; K Ridwelski, Department of Surgery, University of Magdeburg, Magdeburg (current address:
Department of Surgery, Klinikum Dessau); J Gabriel, Department of General and Transplantation Surgery, University of Rostock; K-U Zerbian, Department of Surgery, Kreiskrankenhaus Lüdenscheid; KH Ebert, Department of Surgery, St Martinus-Hospital, Olpe; H Bewersdorf, Department of Medicine I, Ostalbklinikum, Aalen; H-F Weiser, Department of Surgery, Ev.-Luth. Diakoniekrankenhaus Rotenburg; U Schenker, Department of Surgery, ParkKrankenhaus, Leipzig; B Karn, Department of Surgery, Klinikum Bad Salzungen; W Oettinger, Department of Surgery, and W Weber, Department of Medicine, Krankenhaus der Barmherzigen Brüder, Trier; F Schwanghart, Department of Medicine, St Elisabeth Krankenhaus, Bad Kissingen; P Mattes, Department of General Surgery, Städt. Krankenanstalten Esslingen; K Fleischer, Department of Medicine, Helfensteinklinik, Geislingen; J Kuhlgatz, Department of Surgery, Klinikum Fulda (current address: Department of Surgery, Albert-Schweitzer-Krankenhaus Northeim); N Heni, Department of Medicine, D Höfer, Department of Surgery, Kreiskrankenhaus Biberach; G Kraatz, Department of Medicine, University of Greifswald; J Vogt, Department of Surgery, St Vinzenz-Krankenhaus Hanau; V Mendel, Department of Surgery, Diakonissenkrankenhaus Flensburg; G Simonis, Department of Surgery, Krankenhaus d. Bundesknappschaft, Püttlingen; J Albrecht, Department of Surgery, Kreiskrankenhaus Schorndorf; M Anlauf, Department of Medicine, Zentralkrankenhaus Reinkenheide, Bremerhaven; E-U Steinhauer, Department of Hematology and Oncology, Städt. Kliniken Kassel; and J Limmer, Department of Surgery, Winterberg-Kliniken, Saarbrücken. 